\title{
Regenerative Cell Technologies for Gingival Recession Treatment
}

\author{
DOI: $10.17691 / \mathrm{stm} 2018.10 .4 .11$
}

Received June 8, 2018

S.P. Rubnikovich, MD, DSe, Professor, Head of the Department of Orthopedic Dentistry and Orthodontics

with a Course of Children Dentistry

Y.L. Denisova, MD, BSc, Professor, Department of Therapeutic Dentistry2;

T.E. Vladimirskaya, PhD, Leading Researcher, Head of the General Pathology Unit';

V.A. Andreyeva, MD, PhD, Associate Professor, Department of Orthopedic Dentistry and Orthodontics with a Course of Children Dentistry';

Z.B. Kvacheva, PhD, Leading Researcher';

G.Y. Panasenkova, PhD Student, Department of Orthopedic Dentistry and Orthodontics with a Course of Children Dentistry';

1.D. Volotovsky, DSc, Academician of the National Academy of Sciences of Belarus; Head of the Laboratory of Cell Molecular Biology ${ }^{3}$

${ }^{1}$ Belarusian Medical Academy of Postgraduate Education, 3 P. Brovky St., Minsk, 220013, Republic of Belarus;

${ }^{2}$ Belarusian State Medical University, 83 Dzerzhinsky Avenue, Minsk, 220116, Republic of Belarus;

${ }^{3}$ Institute of Biophysics and Cell Engineering of the National Academy of Sciences of Belarus,

27 Academicheskaya St., Minsk, 220072, Republic of Belarus

The aim of the study was to assess experimentally the possibility of using mesenchymal stem cells (MSC) and bioplastic material Collost for gingival recession treatment based on the data of morphological alterations in the tissues of pathologically transformed periodontium.

Materials and Methods. Random-bred white female rats (60 specimens) were used as a model in the experiment. The operative intervention was performed in the area of incisors of the upper and lower rat jaws. Before the investigations, 1-2 ml of the adipose tissue were harvested from one specimen under sterile conditions in order to obtain allogeneic mesenchymal stem cells.

All animals were divided into 5 groups (10 rats in each group) depending on the selected method of treatment: group 1 - experimental gingival recession without treatment; group 2 - treatment with physiological solution; group 3 - experimental gingival recession treatment with 7\% Collost gel; group 4-experimental gingival recession treatment with MSC; group 5-experimental gingival recession treatment with MSC and $7 \%$ Collost gel. The control group, intact rats, consisted of 10 laboratory animals with a healthy gingiva. The creation of a model of the experimental gingival recession was carried out by mechanical V-shaped excision of periodontal tissues.

Results. The isolated form of $7 \%$ Collost gel (a bioplastic collagen material) serves in the process of biodegradation as a matrix for the formation of the native connective tissue, provides adhesion of the stem cells and their transformation into pro- and fibroblasts. $7 \%$ Collost gel facilitates the reduction of gingival recession and gingival pocket depth, stimulates the process of epithelization. Injections of cell transplant suspension in physiological solution activate the processes of fibroblast differon cell proliferation and cell transformation. The cell transplant suspension in the sterile bioplastic 7\% Collost gel enhances the gel and stem cell effects, contributes to the elimination of the atrophic and dystrophic changes in the gums, increase of mechanical strength, reduction of gingival recession and gingival pocket depth.

Key words: mesenchymal stem cells; Collost; gingival recession; periodontal disease.

\section{Introduction}

The search for effective methods of periodontal disease treatment is at present a burning problem of modern dentistry. On the one hand, it is determined by a still high prevalence of the disease in the population including young people, and on the other, by insufficiently effective means and methods of treatment suggested today $[1,2]$.

According to $\mathrm{WHO}$, the prevalence of periodontal diseases reaches $90-95 \%$ in adult population, and it makes $94.8 \%$ among the 35-44-year-old residents of the Republic of Belarus [3]. Gingival recession is one of the common forms of periodontal tissue pathology and, according to the data of epidemiological survey conducted in the Republic, is registered in $9.7 \%$ of cases in 15 -year-old patients and in $99.3 \%$ in adults $[4,5]$.

Now, there exist various methods of treating gingival recession using a complex of therapeutic, surgical, orthodontic, and orthopedic procedures, however, the results of observations do not give evidence of longlasting and stable periodontal tissue regeneration $[2,6]$.

Corresponding author: Sergey P. Rubnikovich, e-mail: rubnikovichs@mail.ru 
Perspective directions of the present science include the applications of autologous and allogenic mesenchymal stem cells (MSC) for periodontal tissue regeneration, development of new methods of regenerative therapy, and implementation of them into clinical dentistry, which will enable improvement of treatment efficacy and patients' quality of life [713]. Specialists of many countries carry out diverse investigations in this direction, the success of which depends greatly on the choice of the experimental model [14-19].

Presently, one of the new approaches to the periodontal tissue regeneration is the application of a bioplastic collagen material Collost as a barrier matrix [20]. The gel form of Collost biomaterial is widely used in general surgical practice in the management of chronic wound skin defects of various etiology [21-23]. Application of the collagen Collost gel for gum recession treatment, especially as a scaffold in tissue-engineered constructs is considered as a promising technique.

All the above-said motivates the researchers to carry out grounded experimental and clinical studies on the application of MSC on the collagen gel Collost in dentistry for activating regenerative processes in the periodontal tissues and improving the efficacy of treating patients with gingival recession.

The aim of the study was to assess the character of morphological changes in the pathologically altered periodontal tissues using biotransplant based on the adipose tissue-derived mesenchymal stem cells immobilized on the collagen matrix Collost for treating gingival recession in the experiment on animals.

\section{Materials and Methods}

The experimental studies were carried out in the Research Laboratory of the Belarusian Medical Academy of Postgraduate Education. The operative intervention was performed in the area of incisors of the upper and lower rat jaws.

Non-linear randombred females of white outbred rats $(n=60)$ weighing 200.0-250.0 g were used as a model in the experiment. The rats were housed under standard vivarium conditions according to the sanitary and hygienic rules approved in the Republic of Belarus, and in compliance with the Guide for the Guide for the Care and Use of Laboratory Animals (National Research Council, 2011), and Ethical Principles of the European Convention for the Protection of Vertebrate Animals used for Experimental and Other Scientific Purposes (Strasbourg, 2006).

At the first stage of the investigation, an experimental model of gingival recession was formed surgically in 50 laboratory animals, 10 rats remained intact over the whole period of observations.

Experimental gingival recession was modeled on the vestibular surface in the region of incisors and dentogingival papillar in the upper and lower jaws on the right after anesthesia: intramuscular injection of narcotic analgetics $(0.005 \%$ fentanyl $+0.25 \%$ droperidol in $1: 2$ ratio and a dose of $0.3 \mathrm{ml}$ per $100 \mathrm{~g}$ of body mass).

The operative intervention was performed by mechanical V-shaped excision of the periodontal tissues from the vestibular surface with a round hard metal bur and a portable micromotor. The dentogingival papillar between the incisors was first excised with a round hard metal bur and then with a scalpel in order to form "black triangles".

Before the investigations, 1-2 $\mathrm{ml}$ of the adipose tissue were harvested from one specimen under sterile conditions in order to obtain allogeneic mesenchymal stem cells. MSC isolation, culturing, and transplant preparation were performed in the laboratory of the Institute of Biophysics and Cell Engineering of the National Academy of Sciences of Belarus.

At the second stage, 10 days after the creation of the experimental gingival recession models and completion of the epithelization process, the animals were distributed into groups depending on the administered therapy:

group $1(n=10)$ - induced gingival recession without further treatment;

group $2(n=10)$ - injections of physiological solution into the gingival tissue;

group $3(n=10)$ - injections of $7 \%$ Collost sterile bioplastic collagen material into the gingival tissue;

group $4(n=10)$ - injections of adipose tissue-derived MSC suspension in the physiological solution into the gingival tissue;

group $5(n=10)$ - injections of adipose tissue-derived MSC suspension in the $7 \%$ Collost sterile bioplastic collagen into the gingival tissue.

Animals were withdrawn from the experiment by 5 rats from each group in 25 and 38 days after the gingival recession formation (on days 14 and 28 after the beginning of the study) in compliance with bioethics principles (according to the GLP standards) under intraperitoneal thiopental anesthesia $(1 \mathrm{ml}$ of $5 \%$ sodium thiopental per $100 \mathrm{~g}$ of body mass). Bioptate of the "tooth-periodontal tissue-bone tissue" complex was collected for pathomorphological investigations.

A dento-gingiva-maxillary block of the upper and lower rat jaws was examined in the course of the experiment. The dissected areas were fixed in $10 \%$ neutral formalin for $48 \mathrm{~h}$. The preparations were decalcified with a mixture of formic and hydrochloric acids and subjected to the standard histotechnical treatment after which 3-5 $\mu \mathrm{m}$ sections were prepared from the paraffin blocks and stained with hematoxylin and eosin. Micropreparations were studied and microphotographs were taken using Axio Imager (Carl Zeiss, Germany) and softwaresupported DMLS microscopes (Leica, Germany).

\section{Results}

The efficiency of biotransplant based on MSC immobilized on the $7 \%$ Collost collagen matrix was 


\section{EXPERIMENTAL INVESTIGATIONS}

assessed by analyzing the character of morphological changes in the periodontal tissues in which the experimental model of gingival recession has been surgically formed.

Morphological picture of the intact rat tissues. The gingival channel in the upper jaw is short, without any content. The channel bottom is presented by squamous epithelioid cells, perifocally — with thin-walled capillaries in the tissue of adjacent gingival lamina propria (LP). The junctional epithelium is exfoliated, is represented by a narrow strand of fibrous tissue and epithelioid cells. The free gingiva consists of a keratinized stratified squamous epithelium (SSE), with a narrow strip of a laminated and segmentally exfoliated keratin substance and small bodies of keratohyalin in the cytoplasm of the granular layer. Paleness of the basal cell cytoplasm, smoothed and wide epithelial ridges along the outer margin of the free gingiva are noted. The free gingiva LP is loose, few-celled (fibrocytes, scanty fibroblasts, and single small undifferentiated cells), with diffused and scattered small groups or singly located plethoric capillaries with no signs of inflammatory infiltration. A moderately celled periodontal ligament integrated with the alveolar process periosteum is observed.

In the lower jaw of the intact rats, a gingival pocket of moderate depth without any content is seen. Epitheliocytes and a loose connective tissue are found
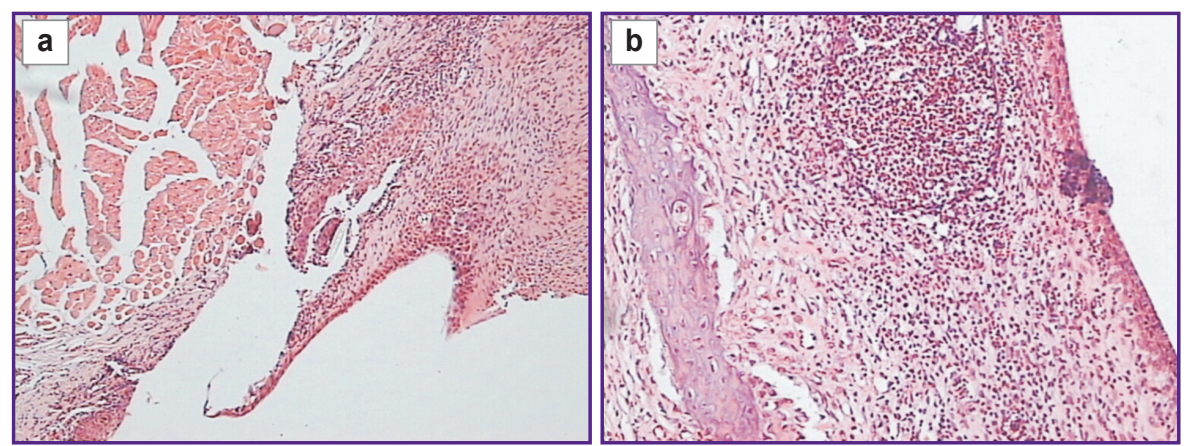

Figure 1. Morphological changes in the animal gingival tissues of group 1 (induced recession without further treatment) on day 14:

(a) in the upper jaw; $x 100$; (b) in the lower jaw; x200
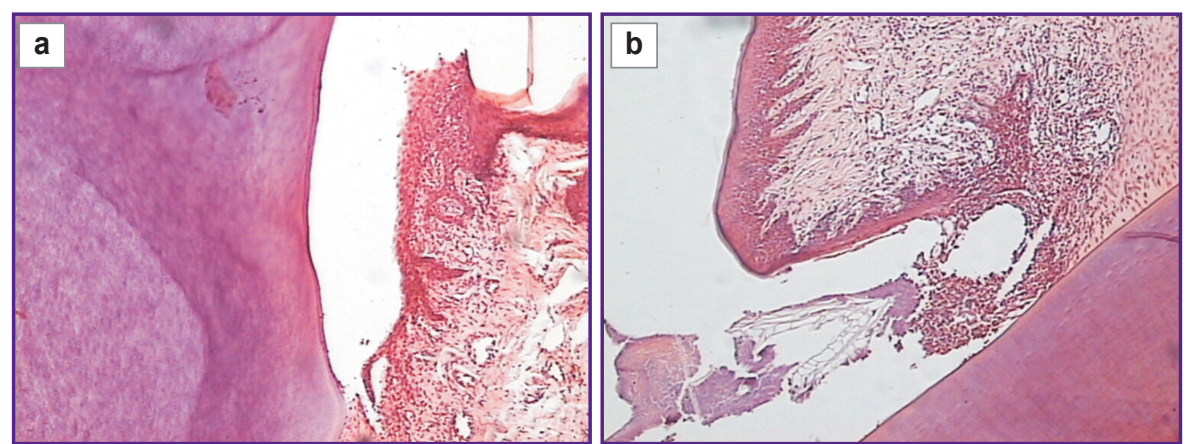

Figure 2. Morphological changes in the animal gingival tissues of group 2 (injection of physiological solution into the gingival tissue) on day 14:

(a) in the upper jaw; x100; (b) in the lower jaw; x100 at the channel bottom. The junctional epithelium is presented by a narrow strip of squamous epithelial cells. The free gingiva consists of keratinized SSE with a narrow strip of corneal layer. The epithelial ridges are short and wide or narrow and elongated along the outer gingival surface. The free gingival LP is composed of the dense shapeless few-celled (fibrocytes, occasionally, fibroblasts) connective tissue with diffusely located narrow capillaries. The periodontal ligament is moderately celled, integrated with the alveolar process periosteum.

In group 1 on day 14 (gingival recession without further treatment): a deep gingival pocket is noted in the upper jaw (Figure 1 (a)). The distal part of the pocket (bottom) is moderately widened, focal epithelium proliferation is observed. The junctional epithelium is presented by a narrow strip of squamous epithelial cells. The free gingiva consists of keratinized SSE with an unevenly narrow strip of the corneal layer. Minimal segmental proliferation of the epithelial basal layer cells is noted. In the perifocal part of the periodontum, moderate fibroplasia with a moderate seroproductive inflammation and the transition to the periodontal ligament and the alveolar process periosteum integrated with it is observed.

In the lower jaw of this group (Figure 1 (b)), the gingival sulcus is moderately deep, the gingival channel is slightly widened. The distal part of the channel is slightly widened, the bottom in some cases is thickened due to SSE hyperplasia with papillomatosis. The junctional epithelium is torn off, presented by a narrow strand of squamous epithelial cells. The free gingival SSE is keratinizing with unevenly narrow strip of the corneal layer, with short wide or narrow epithelial ridges in the outer gingival part. The gingival LP consists of the loose connective tissue without inflammatory infiltration, with moderately plethoric capillaries arranged singly of in chains. A marked seropurulent inflammation was found in one of the specimen with the formation of microabscess in the periapical part of the tooth and the transition to the alveolar process periosteum.

In group 2 on day 14 (injections of physiological solution into the gingival tissue): the gingival sulcus in the upper jaw is deep, the gingival channel is narrow (Figure $2(a)$ ). 
The junctional epithelium is torn, seen as a narrow strand of squamous epithelial cells. The free gingival SSE is keratinizing with a swollen and segmentally exfoliated corneal layer. In the distal part and at the bottom, small foci of edema and epithelium loosening with hydropic degeneration of the cells are fixed. The gingival LP is found as a few-celled connective tissue with moderate edema, swelling, and loosening of the collagen fibers, constriction of the blood capillaries, and moderate ectasia of the lymphatic capillaries. Edema and loosening of the proximal segment of the periodontal ligament are observed.

In the lower jaw in this group, the gingival sulcus of a moderate depth is seen. The gingival channel is slightly widened. The channel bottom consists of a narrow segment of a loose connective tissue with a minimal serous inflammation. The junctional epithelium is torn, with a narrow strand of squamous epithelium, there is a seroproductive inflammation perifocally in the bottom area. The free gingival SSE is keratinizing, with a narrow strand of the segmentally minimally swollen keratin. Multifocal minimal proliferation of the basal layer cells is noted. The free gingival LP consists of a few-celled loose connective tissue with widened lymphatic capillaries, focal seroproductive inflammation, in the distal part there are strands of densely packed thin fibers located compactly, loosely, multifocally.

\section{In group 3 on day 14} (injections of $7 \%$ Collost): the gingival sulcus in the upper jaw is not deep, the gingival channel is moderately widened, without any gel in its lumen (Figure 3 (a)).

Focal proliferation of the epithelial cells is observed at the bottom of the gingival channel. Junctional epithelium is torn, with a narrow strand of epithelial cells. The free gingival SSE is keratinizing with an uneven strip of the corneal layer. The free gingival LP consists of a few-celled loose connective tissue with small foci of narrow capillaries, without blood components in their lumen and with no signs of inflammation. The periodontal ligament is wide, few-celled, integrated with the periosteum of the alveolar process.

In this group, the gingival sulcus in the lower jaw is not widened, the channel is not deep. Small strands of the gel with the foci of rarefaction are observed in its lumen (Figure 3 (b)). The junctional epithelium is torn, presented by a narrow strand of a loose connective tissue with perifocal hyperplasia of the epithelial cells. The free gingival epithelium is keratinizing, with a narrow strip of the corneal layer, stratified and segmentally exfoliated. Non-uniform SSE hypertrophy is noted along the inner surface at the bottom of the gingival channel due to hyperplasia of the granular, spinous, and segmentally basal layers with thin epithelial ridges. The free gingival LP represents a loose shapeless connective tissue. The periodontal ligament is few-celled, integrated with the periosteum of the jaw alveolar process.

In group 4 on day 14 (injections of MSC suspension in physiological solution): the gingival sulcus in the upper jaw is wide, the gingival channel is deep (Figure $4(\mathrm{a})$ ). The attachment part is presented by a strand of epitheloid cells with their hyperplasia in the distal part which is more evident in the bottom area, with perifocal fibroplasia of the gingival LP: with multiple profibroblasts which spread to the periodontal ligament and the alveolar process periosteum. The free gingival consists of the keratinized SSE, with a segmentally stratified and/or exfoliated corneal layer. Foci of neoangiogenesis have the form of small groups and chains of ectactic plephoric capillaries. No signs of inflammation are noted. The periodontal ligament is densely celled.
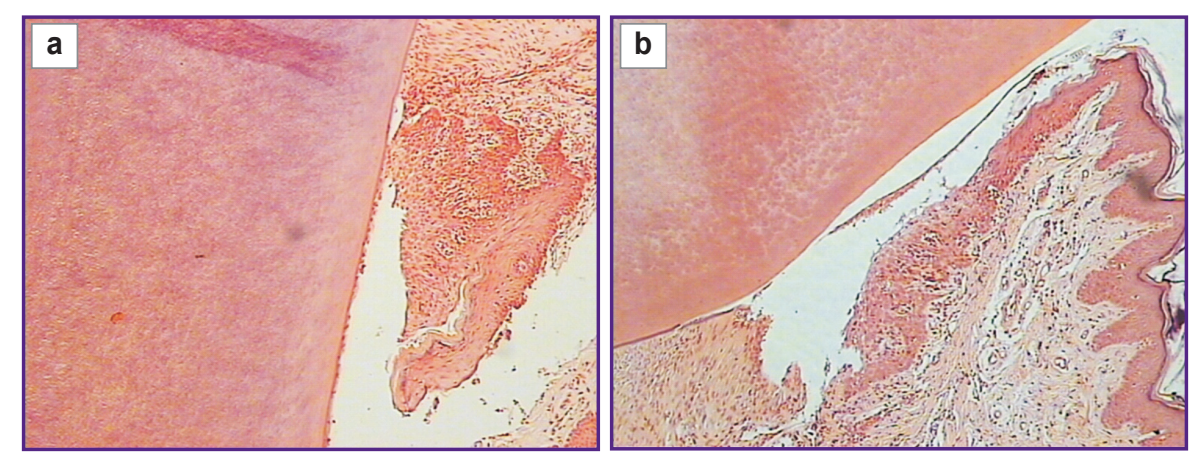

Figure 3. Morphological changes in the animal gingival tissues of group 3 (injections of $7 \%$ Collost gel) on day 14 :

(a) in the upper jaw; x100; (b) in the lower jaw; x100
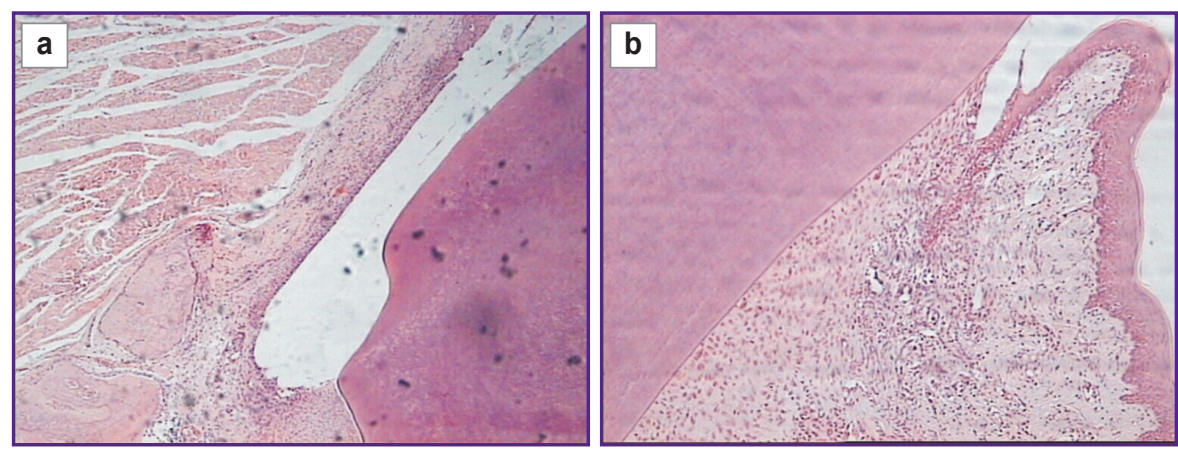

Figure 4. Morphological changes in the animal gingival tissues of group 4 (injections of MSC suspension in physiological solution) on day 14:

(a) in the upper jaw; x100; (b) in the lower jaw; x50 


\section{EXPERIMENTAL INVESTIGATIONS}

The gingival sulcus in the lower jaw in this group is relatively wide, the channel is deep without any content (Figure 4 (b)). The channel bottom consists of a narrow strip of the loose connective tissue with single capillaries and segmentally of the proximal part of the periodontal ligament. At the bottom of the gingival pocket, the onset of loosely located fibers formation can be noticed. The junctional epithelium is torn, seen as a narrow strip of the mature connective tissue and epithelium. The free gingival consists of keratinized SSE with ordinary or smoothed epithelial ridges, the LP is composed of the loose mature connective tissue with scanty functioning capillaries and an area in the distal part. At the bottom of the gingival channel, predominance of small undifferentiated cells without signs of inflammation is noted. The periodontal ligament is hypercellular, its distal part is widened and integrated with the alveolar process periosteum.

In group 5 on day 14 (injections of MSC suspension in $7 \%$ Collost gel): the gingival channel in the upper jaw is ordinary or short, no content in the lumen or single small clumpy fragments of the gel with microfocal clarification and a tiny area of fibrosis and sclerosis are encountered (Figure 5 (a)). The bottom of the gingival channel is widened, presented by epithelial cells and distally located narrow plane strip of a mature few-celled connective tissue. The junctional epithelium
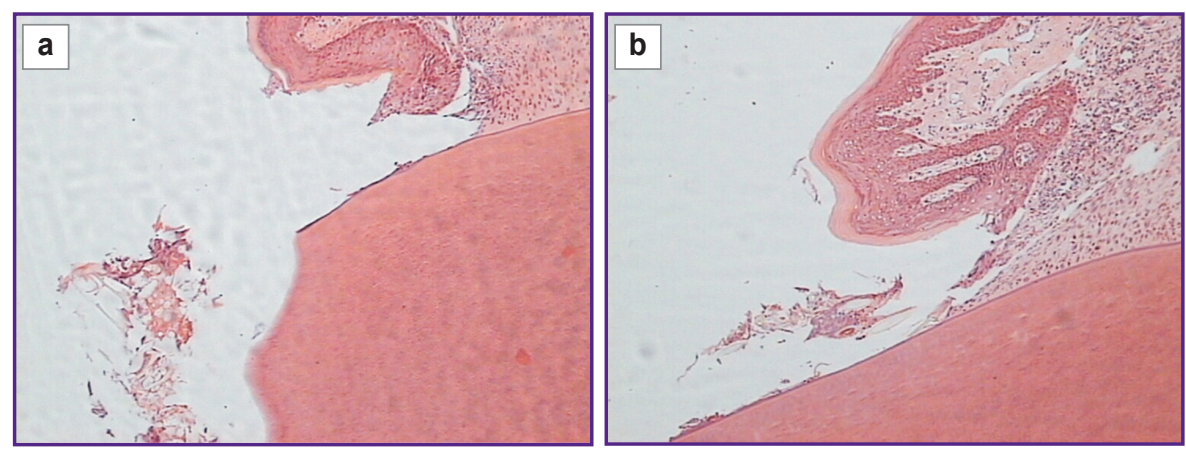

Figure 5. Morphological changes in the animal gingival tissues of group 5 (MSC suspension $+7 \%$ Collost gel) on day 14 :

(a) in the upper jaw; $x 100$; (b) in the lower jaw; $x 400$
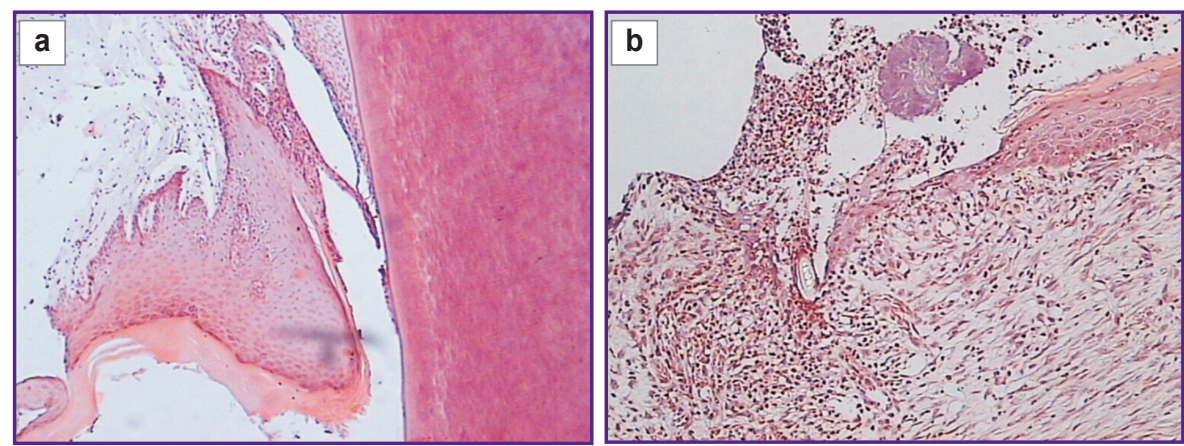

Figure 6. Morphological changes in the animal gingival tissues of group 1 (induced recession without further treatment) on day 28:

(a) in the upper jaw; x100; (b) in the lower jaw; x200 is presented by a narrow strand of small undifferentiated cells, fibroblast precursors, and a perifocal relatively wide strip of epithelial cells. The free gingiva consists of keratinized SSE with ordinary or short and smoothed epithelial ridges, with minimal segmental hyperplasia of the basal cells, the free gingival LP is composed of a loose few-celled connective tissue with small foci of narrow capillaries without blood components in their lumen and any signs of inflammation. The periodontal ligament is wide, few-celled, and integrated with the alveolar process periosteum.

In this group, the gingival channel in the lower jaw is short, a lumpy gel is seen in the lumen: loosened and segmentally fragmented with spicular fibrin strands, small foci of mononuclear infiltration including segmentonuclear leukocytes (SNL) (Figure $5(b)$ ).

The junctional epithelium is exfoliated, has a polymorphic histostructure: a small area of epithelioid cells with a homogeneous intercellular substance at the bottom of the gingival channel, the proximal area has a loose few-celled connective tissue, foci of thin-walled ecstatic vessels with proliferation and desquamation of endotheliocytes, small and undifferentiated cells are diffusely located. The free gingiva consists of keratinized SSE with a relatively broad corneal layer, the free gingiva LP is composed of a mature few-celled connective tissue with widened Iymphatic capillaries and without inflammatory infiltration. The gingival channel bottom is presented by a narrow strand of the loose fine-meshed connective tissue and in the distal part by a strip of epithelial cells.

In group 1 on day 28: the gingival sulcus in the upper jaw is deepened and forms a gingival pocket (Figure 6 (a)). The junctional epithelium is seen as an unevenly narrow SSE strip with focal loosening at the bottom of the gingival pocket. The free gingiva consists of keratinized SSE with a nonuniformly narrow corneal layer and low wide epithelial ridges, the gingival LP is composed of a loose connective few-celled (fibrocytes, rarely - fibroblasts, diffusely scattered lymphocytes, and plasmatic cells) tissue with lymphatic capillary ectasia. The periodontal ligament is unevenly wide, moderately celled, integrated with the periosteum of the alveolar process with osteocyte vesiculation and swelling of the intercellular basal substance. 
The gingival sulcus in the lower jaw in this group is deepened and slightly widened without any content (Figure 6 (b)). Fibroblast swelling and infiltration with eosinophilic leukocytes are noted focally in the subepithelial zone. The junctional epithelium is torn, presented by a narrow strand of the connective tissue, in one case it is in a state of edema, segmentation, and hydropic necrosis. The free gingiva consists of keratinized SSE with low and wide epithelial ridges or, focally, with thin long ridges, in one case it is in a state of subtotal edema and hydropic necrosis of the epithelial cells with microabscess. The gingival LP is presented by a few-celled connective tissue, in one case with SNL infiltration. The periodontal ligament densely celled and integrated with the alveolar process periosteum with osteocyte vesiculation and swelling of the intercellular ground substance of bone tissue.

In group 2 on day 28: the gingival sulcus in the upper jaw is deepened (Figure 7 (a)). The junctional epithelium exfoliated from the dental root, is seen as an extremely narrow strip of edematous connective tissue with few fibroblasts and single lymphocytes. The free gingiva consists of keratinized SSE with a narrow strip of a corneal layer and wide low focally elongated epithelial ridges. Noted are swelling and paleness of the epithelial cells, being especially intensive in the spinous layer, and minimal proliferation of the basal layer cells. The gingival LP represents a few-celled connective tissue in a state of the intensely marked edema with swelling and fibroblast elimination, fragmentation, swelling, and elimination of the collagen fibers. The periodontal ligament is densely celled with swollen pale-colored fibroblasts, integrated with the alveolar process periosteum.

In the lower jaw, the gingival sulcus is deepened and forms an expanded gingival pocket (Figure 7 (b)). In the lumen of the pocket there are segments of hair shafts and a relatively large area of inflammatory exudates from mononuclears (including SNL) which extends to the bottom of the gingival pocket and reaches the proximal segment of the periodontal ligament. The junctional epithelium is torn away from the dental root, is seen as a narrow strip of dystrophic SSE. The free gingiva consists of keratinized SSE with a segment of a narrow stratified and exfoliated corneal layer, with wide low epithelial ridges, the gingival LP is composed of a loose edematous few-celled connective tissue with swollen fibroblasts, few lymphocytes, single eosinophilic SNL, ectasia and venule plethora, foci of cellular and connective component elimination. The periodontal ligament is edematous, with swollen pale-colored fibroblasts, integrated with the edematous periosteum of the alveolar process in which swelling and homogenization of the basal substance of bone and osteocyte vesiculation are noted.

In group 3 on day 28: the gingival sulcus in the upper jaw forms a gingival pocket mainly without any content (Figure $8(a)$ ). In the proximal part, small lumpy bodies of the gel are fixed. Segments of lumpy gel are found mainly along the margin of the dental root with the signs of resorption. The junctional epithelium is exfoliated from the root margin, presents as a narrow strand of squamous epithelial cells. The free gingiva consists of keratinized SSE with unevenly narrow strip of the corneal layer, the gingival LP is composed of a few-celled homogenized connective tissue (cells: fibrocytes, fibroblasts) with fine thin-walled capillaries without signs of inflammatory infiltration. The moderately celled periodontal ligament is integrated with the alveolar process periosteum.

In the lower jaw, the gingival sulcus is deepened and
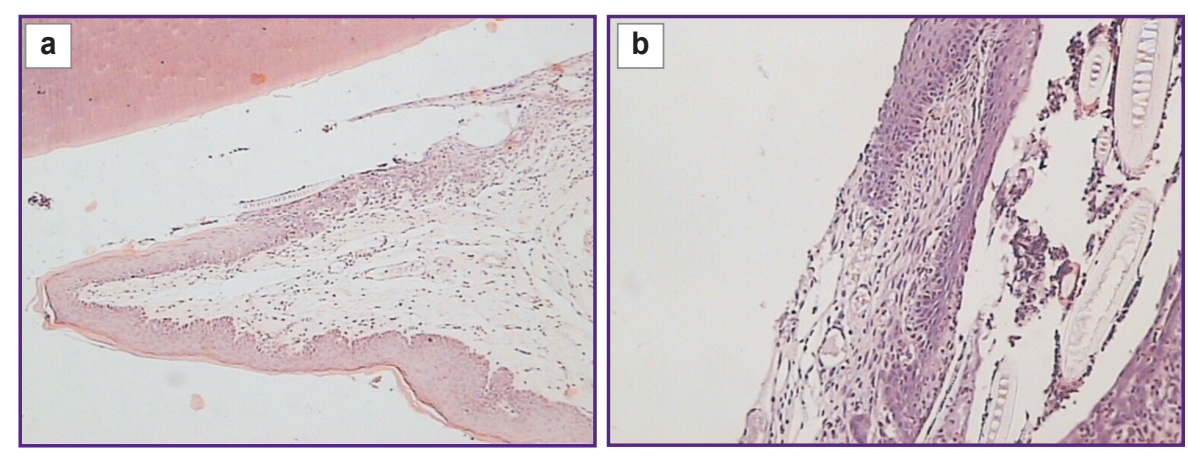

Figure 7. Morphological changes in the animal gingival tissues of group 2 (injection of physiological solution into the gingival tissue) on day 28:

(a) in the upper jaw; x100; (b) in the lower jaw; x200
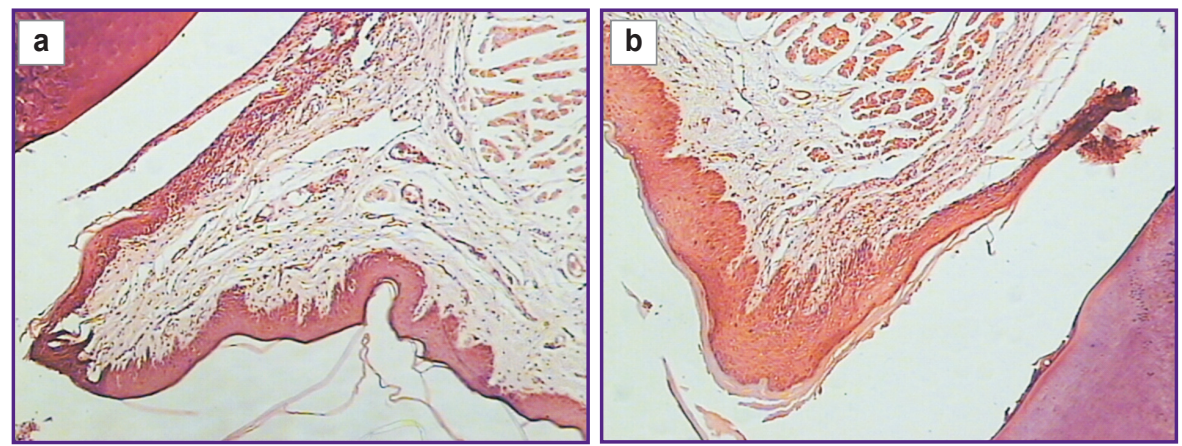

Figure 8. Morphological changes in the animal gingival tissues of group 3 (injections of $7 \%$ Collost gel) on day 28 :

(a) in the upper jaw; x100; (b) in the lower jaw; x200 


\section{EXPERIMENTAL INVESTIGATIONS}

focally widened (Figure 8 (b)). Polymorphic gel lumps are observed in the gingival pocket and tissue. The junctional epithelium is presented by a narrow strip of the squamous epithelial cells. The free gingiva consists of keratinized SSE with a thin strip of the pale-colored corneal layer. Swelling and homogenization of spinous cells (focally - vesiculazation), focal proliferation, swelling and a pale color of the basal cells, presence of thin and blunt-pointed epithelial ridges are noted. The gingival LP is presented by a densely celled (fibrocytes, fibroblasts) connective tissue with diffusely located narrow capillaries. The periodontal ligament is moderately celled, integrated with the periosteum of the alveolar process, with sharp lines of osteon lamellae and osteocyte vesiculation.

In group 4 on day 28: the gingival sulcus in the upper jaw is deepened, the gingival pocket is narrow without any content (Figure $9(\mathrm{a})$ ). The junctional epithelium is exfoliated (torn). A relatively wide matrix, pale-colored fibroblasts and epithelioid cells with admixture of the densely celled connective tissue layers with the swollen pale-colored intercellular substance, diffusely located scanty small and undifferentiated cells are noted. The free gingiva consists of keratinized SSE with unevenly
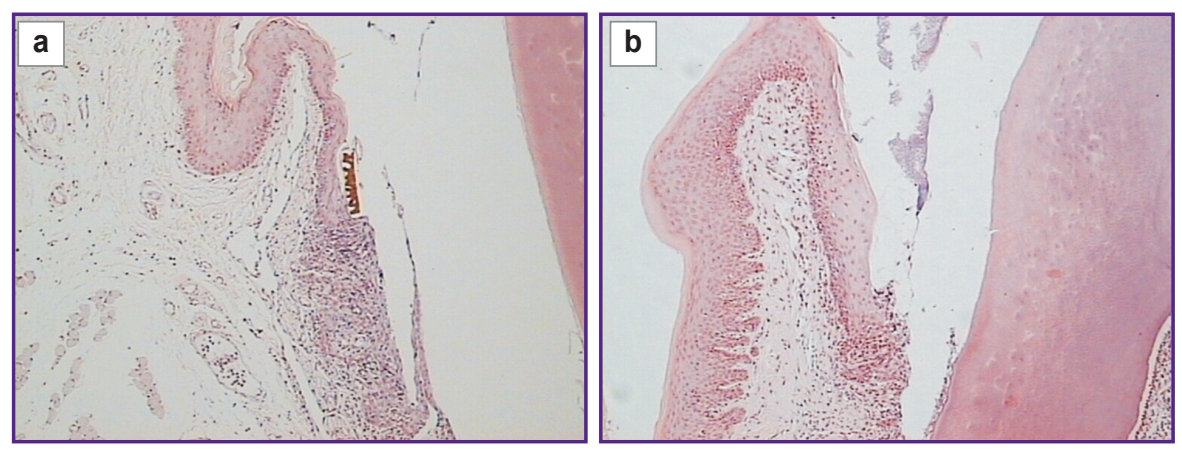

Figure 9. Morphological changes in the animal gingival tissues of group 4 (injections of MSC suspension in physiological solution) on day 28:

(a) in the upper jaw; x100; (b) in the lower jaw; x100 thickened strip of the segmentally exfoliated corneal layer. Edema and swelling of intercellular matrix and the cells of epithelial layers with their discomplexation are noted as well as swelling and pale color of the basal cells with their minimal proliferation and enlarged epithelial ridges, thin in some places. The gingival LP consists of a few-celled heavily edematous connective tissue, with swelling of the cells and connective structures, with their focal and diffuse elimination and moderately expressed neoangiogenesis. The periodontal ligament is non-uniformly thickened, densely celled, moderately edematous, with swollen fibroblasts and small undifferentiated cells (stem cells). It is integrated with the periosteum of the alveolar process in which foci of small undifferentiated cells with the admixture of single plasmocytes are also encountered.

In the lower jaw, the gingival sulcus is deep, with a bag-shaped or large gingival pocket (Figure $9(b))$. The junctional epithelium is torn, presented by a strand of epithelioid cells with forming epithelial ridges. The free gingiva consists of keratinized SSE with a narrow strip of the segmentally exfoliated and stratified corneal layer, the gingival LP is composed of moderately and few-celled edematous connective tissue with foci of cell elimination and single small undifferentiated cells. The periodontal ligament is unevenly thickened, edematous, densely celled with fibrocyte dominance, minimal angiogenesis of the jaw process, integrated with the alveolar process periosteum.

In group 5 on day 28: a gingival pocket in the upper jaw is wide and shallow (Figure 10 (a), (b)). Its bottom consists of few-celled connective tissue with scanty small hyperchrome undifferentiated cells, mainly with
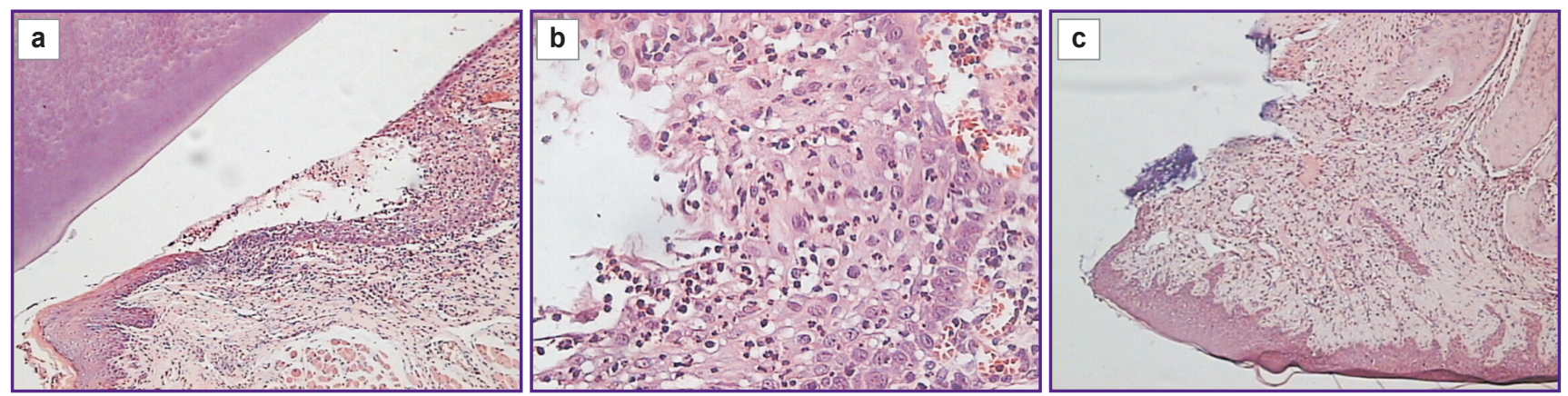

Figure 10. Morphological changes in the animal gingival tissues of group 5 (MSC suspension $+7 \%$ Collost gel) on day 28 : (a) in the upper jaw; staining with hematoxylin and eosin; gingival pocket is wide and shallow, in the lumen: mucus with penetration of lymphocytes, segmentonuclear leukocytes, and scanty small undifferentiated cells (reducing stem cells); x100; (b) in the upper jaw; staining with hematoxylin and eosin; gingival pocket bottom consists of a few-celled connective tissue with scanty small hyperchrome undifferentiated cells (reducing stem cells) with areas of epithelioid cells forming epithelioid ridges; x400; (c) in the lower jaw; x400 
the areas of epithelioid cells forming epithelioid ridges. Gel in the gingival pocket and periodontal tissues is not visualized.

The junctional epithelium consists of a narrow strand of the few-celled connective tissue with homogeneous intercellular matrix, single undifferentiated cells and SNL. The free gingiva consists of keratinized SSE with a relatively wide corneal layer and a narrow inner strip of the granular layer cells, with plenty of fine keratohyalin grains. Vesiculation of the spinous and basal layer cells with intercellular matrix homogenization and low wide epithelial ridges is noted. The gingival LP consists of a few-celled strongly thickened connective tissue with scanty tiny undifferentiated cells tending to differentiate into fibroblasts, with moderate neoangiogenesis. The periodontal ligament is non-uniformly wide, densely celled (fibrocytes and, predominantly, fibroblasts with small foci of swollen fibroblasts and their precursors), integrated with the alveolar process periosteum of the normally structured jaw.

The gingival pocket in the lower jaw is moderately widened and shallow without any content (Figure 10 (c)). The junctional epithelium is torn, seen as a narrow strand of epithelial loosely packed cells which segmentally compose the gingival pocket bottom. The free gingiva consists of keratinized SSE with a thin corneal and compact granular layer. Focal proliferation of the basal layer cells with formation of thin epithelial ridges is observed. The gingival LP is presented by a loose densely celled connective tissue (fibrocytes, predominantly fibroblasts, profibroblasts, plasmatic cells, single SNL, and numerous reducing undifferentiated cells). Moderately marked neoangiogenesis is fixed. The periodontal ligament is extremely wide, densely celled, consists of fibrocytes, fibroblasts, and, predominantly, epithelioid cells with scanty reducing undifferentiated cells, is integrated with the alveolar process periosteum of the normally structured jaw.

Thus, the analysis of morphological changes in the animal periodontal tissues, in which a model of gingival recession has been formed, made it possible to assess the results of using different agents for transplantation of various biomaterials and their combinations.

Local introduction of physiological solution into the gingival tissues causes edema and swelling of the tissue and cellular components of the gingiva and periodontium which impairs their mechanical and biophysical function, promotes the development of dystrophic changes (hypropic dystrophy), and later development of inflammatory processes (periodontitis).

The bioplastic collagen material, $7 \%$ Collost gel, in the process of degradation in the isolated form serves as a matrix for the formation of the native connective tissue, provides adhesion of the stem cells and their transformation into pro- and fibroblasts. Collost contributes to the reduction of gingival recession and pocket depth, stimulates the process of epithalization.

Injections of the MSC cell transplant suspension, in the physiological solution activate cell proliferation and transformation of fibroblast differon cells.

The suspension of the stem cell transplant on the sterile Collost bioplastic collagen enhances effects of the gel and stem cells, facilitates elimination of atrophic and dystrophic alterations in the gingiva, enhacement of the mechanical component, reduction of gingival recession and pocket depth.

\section{Conclusion}

The results of our investigation convincingly demonstrate that a combination of the cellular transplant suspension, mesenchymal stem cells, and sterile bioplastic collagen material, $7 \%$ Collost gel, may serve as an up-to-date perspective remedy for gingival tissue regeneration.

Study funding. The work was not supported by any sources.

Conflicts of interest. The authors have no conflicts of interest to declare.

\section{References}

1. Alyamovskiy V.V., Shestakova L.A., Yarygin E.I., Shmidt P.A., Lazarenko L.I. Use of cord blood stem cells of rat's fetal in the inflammatory and destructive processes in periodontal tissues. Institut stomatologii 2014; 1(62): 103105.

2. Musienko A.I., Musienko S.I., Kushnir D.V., Musienko A.A. Complex approach to planning treatment of periodontal diseases by growth factor. Stomatologiya Kazakhstana 2014; 3(4): 67-68.

3. Dedova L.N., Denisova Y.L., Kandrukevich O.V., Solomevich A.S., Rosenik N.I. The prevalence of periodontal diseases, root caries, dentine sensitivity and dentoalveolar deformities in the republic of belarus based on the results of examining the population aged 35-44, 45-54 and 55-64 years. Stomatolog. Minsk 2016; 1(20): 9-15.

4. Dedova L.N. Systematics of periodontal diseases. Stomatologicheskiy zhurnal 2002; 2: 2-6.

5. Denisova Yu.L. Modern orthodontic actions in complex treatment of gingiva recession at the patients with malocclusion. Parodontologiya 2008; 4(49): 74-79.

6. Denisova Y.L., Vladimirskay T.E. Experimental proof of vacuum-laser therapy in the complex treatment of patients with periodontal disease in combination with dentofacial anomalies and deformation. Voennaya meditsina 2013; 1(26): 103-107.

7. Alexeeva I.S., Volkov A.V., Kulakov A.A., Goldshtein D.V. Clinical and experimental study on the use of combined cell transplant on the basis of multipotent mesenchymal stromal cells of adipose tissue in patients with severe deficiency of jaws bone tissue. Kletochnaya transplantologiya $i$ tkanevaya inzheneriya 2012; 7(1): 97-105.

8. Barmasheva A.A., Nikolaenko N.S., Samusenko I.A., Orekhova L.Yu., Pinaev G.P. A comparative study of the influence of skin fibroblasts and bone marrow stromal cells included in collagen gel on gingiva regeneration. Parodontologiya 2012; 17(4): 20-25. 


\section{EXPERIMENTAL INVESTIGATIONS}

9. Bukharova T.B., Arutyunyan I.V., Shustrov S.A., Alekseeva I.S., Fedyunina I.A., Logovskaya L.V., Volkov A.V., Rzhaninova A.A., Grigor'yan A.S., Kulakov A.A., Goldshtein D.V. Tissue-engineering design based on multipotent stromal cells of adipose tissue and "Osteomatrix" material for bone tissue regeneration. Kletochnye tekhnologii $v$ biologii i meditsine 2011; 3: 167-173.

10. Manashev G.G., Lazarenko L.I., Yarygin E.I., Mutaev E.V., Bondar V.S. Perspectives of using the stem cells in therapy of periodontal tissues disease. Sibirskoe meditsinskoe obozrenie 2012; 4(76): 3-6.

11. Rubnikovich S.P., Khomich I.S. The use of bone grafts and bone substitutes to eliminate defects and augment jaw bones in dental implantology and periodontology. Stomatolog. Minsk 2014; 1(12): 77-86.

12. Rubnikovich S.P., Khomich I.S. The use of bone grafts and modern bone substitutes in oral surgery. Stomatolog. Minsk 2014; 4(15): 56-57.

13. Stem cells in dentistry. Sovremennaya stomatologiya 2012; 2: 28-30.

14. Kutsevlyak V.F., Kutsevlyak V.I., Omelchenko E.A., Zabirnyk A.S., Tsyganova I.V. Directional regeneration of alveolar bone deffects using stromal cells of bone marrow with kollapan substrate on experimental animals. Vestnik problem biologii i meditsiny 2015; 3(2): 368-374.

15. Perova M.D., Gajvoronskaya T.V., Karpjuk V.B., Tropina A.V. Replacement evaluation of different periodontal defects using stromal vascular fraction of lipoaspirate. Kubanskiy nauchnyy meditsinskiy vestnik 2013; 6(141): 142148.

16. Rubnikovich S.P., Vladimirskaya T.E., Shved I.A., Veyalkina N.N. Method modeling of experimental periodontitis in animals. Meditsinskiy zhurnal 2011; 1(35): 97-101.

17. Tumanov V.P., Zhakota D.A., Korchagina N.S. 30year experience of development and application of cell technologies in clinical practice. Plasticheskaya khirurgiya $i$ kosmetologiya 2012; 3: 433-449.

18. Sel'skaya B.N., Musina L.A., Kamilov F.Kh. Experimental effect of collagen-containing medication on skin morphology. Kazanskiy meditsinskiy zhurnal 2017; 98(6): 962-967, https://doi.org/10.17750/kmj2017-962.

19. Kamilov F.Kh., Selskaya B.N., Danilova O.V., Kapouler O.M. Metabolism of collagen in the skin of experimental animals at interdermal injection of unmodified bovine collagen of type I. Vestnik Udmurtskogo universiteta. Seriya Biologiya. Nauki o Zemle 2017; 27(3): 356-361.

20. Metod napravlennoy tkanevoy regeneratsii $v$ parodonto-alveolyarnoy rekonstruktsii [Method of directed tissue regeneration in periodontal-alveolar reconstruction]. Pod red. Orekhovoy L.Yu. [Orekhova L.Yu. (editor)]. Moscow: Literra; 2017.

21. Komarov A.N., Kezina L.P., Silina E.V., Gabitov R.B., Orlova A.S., Koreyba K.A. The clinical effectiveness of bioplastic material based on type I collagen for treatment of pressure ulcers in neurorehabilitaion patients: randomized comparative study. Vestnik vosstanovitelnoy meditsiny 2017; 2(78): 74-83.

22. Stupin V.A., Silina E.V., Gorskij V.A., Gorjunov S.V., Zhidkih S.Yu., Komarov A.N., Sivkov A.S., Gabitov R.B., Zolotareva L.S., Sinel'nikova T.G., Barancevich E.R., Bogomolov M.S., Korejba K.A., Bogdanov E.A., Krivihin V.E., Bakunov M.Yu., Eliseeva M.E., Krivihin D.V. Efficacy and safety of collagen biomaterial local application in complex treatment of the diabetic foot syndrome (final results of the multicenter randomised study). Khirurgiya. Zhurnal im. N.I. Pirogova 2018; 6: 91-100, https://doi.org/10.17116/ hirurgia2018691-100.

23. Silina E.V., Stupin V.A., Zolotareva L.S., Komarov A.N. Native collagen application in clinical practice for chronic wounds treatment. Khirurgiya. Zhurnal im. N.I. Pirogova 2017; 9: 78-84, https://doi.org/10.17116/hirurgia2017978-84. 